\title{
THE APPLICATION OF A STANDARD OF PERFECTION TO ORAL RESTORATION.-BRIDGE-WORK
}

\author{
By JAMES KENDALL BURGESS, D.D.S., New York City
}

(Read before the American Dental Association, Los Angeles, California, July 17-21, 1922)

$\mathrm{T}^{\mathrm{H}}$ $\mathrm{HE}$ need has long been felt of some form and degree of standardization in the work of partial oral restoration and the subject has frequently been mentioned in convention hall and journal but no definite or worth-while result has come out of such perfunctory discussions as have been brought forward periodically and spasmodically nor indeed does any serious effort seen to have been made to that end. This seems to be due to two primary causes. First, while such need has been felt by those restless a1ıd resistless few who are never satisfied with present achievementswith the level upon which they find themselves and their profession, but who are seeking always the openings, rugged and unexplored through which they may climb to greater heights and attainments-it has not been able to force itself upon the consciousness of the great mass of the profession who, to change the figure, have been content merely to float with the tide or to gather in little eddies about this or that man with his system or method or hobby or fetish, as driftwood gathers about a common center and floats and swirls in the more secluded and quiet edges of the stream, until the storms of criticism drive them upon the shore to bleach in the wind and sun of scientific investigation and progress. The second cause is that no Moses has arisen to lead us, weary wanderers that we are, out of the wilderness. Those who have essayed the task of leadership have fash- ioned golden calves for our worship or erected for us alters to the unknown gods. But no man has come forward to lead us along the straight and narrow way to the promised land of scientific achievement. Some have made suggestions but have secmed to lack definite convictions or the courage that acts as a driving force behind such convictions as they have had. And so it comes to pass that many decades after the introduction of bridge-work as a means of replacing lost parts of the human denture we find the whole subject in an uncongealed statea church with no creed; a business with no governing principles; an organization with some by-laws but no constitution; a game with no rules for its playing! We are in the anomalous position of trying to produce something with no standardized ideals as a basis of our efforts, or ideas of what it is we are trying to achieve, or the whys and wherefores of our procedures; and consequently with no standard by which to estimate and compare the values of our own production or those of our confreres. Thus there have grown up several schools, numerous divisions and sub-divisions and many fads and "isms" pertaining to oral restoration, and one man or school with a penchant for one phase of endeavor and one for another, with the result that most of our productions are one-sided-excellent no doubt in respect to the particular feature most attractive to the producer but deficient in others 
that are of equal and in many cases of greater importance. Such a state of affairs is distressingly unworthy of so vital and wonderful a part of the human organism as its dental apparatus with the dramatic possibilities of its mechanical perfection and performance and the poetic beauty of its esthetic and cosmetic excellence. I have found my own release from this intolerable state through what I have chosen to call a standard of perfection. The idea, frankly, is drawn from the producers of fine stock whose specimens as observed in the show rooms are bred both for practical and esthetic purposes. These producers know what the practical purposes are and have a keen sense of esthetic values and they know how to breed for form, size, color, etc., in the various parts as well as of the specimen as a whole in order to serve these purposes, practical and esthetic. Pooling ideas as to details and taking the best of each, they arrive at conclusions pertaining to each individual part and the relations of part to part and of each to the whole which, being reproduced, would constitute the ideal or perfect specimen. Thus every detail is standardized and recorded for the guidance of all and this record or guide is called the standard of perfection. By its terms and specifications are valued and compared all the specimens of a given class and their relative values estimated that every producer may know the standards to the minutest detail to which he must breed if he would produce these values and enter into competition.

Is there any reason why we should be l. ss astute than these men who engage in a calling confessedly upon a more material level? I am persuaded that if the dentist is to be as successful in achieving the ends of his calling as is the practical man of affairs he must use the same wisdom and judgment and discretion. We must have our own standard of perfection-such a standardization and codification of ideals, fundamental principles, and ideas through which to give them expression as will serve as a guide to the production of the greatest possible service in its most comprehensive meaning and comprising every element that enters into it. On what shall we base such a standard? On a knowledge obviously of what constitutes service, the elements that enter into it and the operation of those forces and factors through which it is produced. Service, as it pertains to our efforts, means the reestablishment in the highest possible degree of physical integrity and function and the provision for their perpetuation; and in order that we may understand what re-establishment means we must first know physical integrity and function in the normal that when deviation and deterioration occur we may have a definite goal toward which to work in our efforts at rehabilitation.

Let us make a brief survey then of these matters. The first thing we discover is that the dental apparatus is a part of the human body; composed of the same materials that enter into the construction of other parts of the body; amenable to the same laws of growth and development; connected with and nourished by the same circulatory system, playing its individual part in the maintainance of the organism, subject to the same reactions from processes going on in the organism and to the same degenerative influences. Since it is only after accident or deterioration that we are called into service, our restorative efforts are always in connection with pathological conditions or relations or both. All such remedial efforts - efforts directed toward the correction of defects and deficiencies and derangements in the living organism-partake of the nature of surgery. It is true that these corrections are brought about more or less by mechanical means; but so are all surgical operations-the laparotomy, the amputation, the tonsillotomy, etc.,-mechanical procedures. Since we are dealing with the living organism then, and directing our efforts to the rehabilitation 
of its integrity and function, and since this is a surgical procedure, it is clear that surgery must be accounted one of the foundation principles on which we must base our efforts at oral restoration.

Coming to the consideration of the practical relation of the dental apparatus to the human organism, we find it located at the beginning of the alimentary tract. It is into this passage way that the nutriment for the sustenance of the body is introduced and where those physical and chemical changes take place in these nutrient materials that fit them for assimilation by the body. In contemplating these processes it is readily understood that the rapidity and certainty with which the necessary chemical changes take place depend in large measure upon the proper comminution or physical preparation of the food material for chemical attack by the digestive secretions - the more complete the grinding and pulpifying process, the greater the amount of food surface exposed to chemical attack, and the more complete the digestive process in the time nature allots to it; and with the less strain on the digestive apparatus. Further consideration reveals that the oral cavity - the very beginning of the alimentary tract--is the place where this grinding and pulpifying process takes place; that the dental equipment is the apparatus by means of which it is accomplished; and that nature has formed, arranged and related the parts of this apparatus for that definite and particular service to the organism. This part of the digestive process, then, is purely mechanical, performed by a mechanical apparatus constructed by nature for the specific purpose, on the highest engineering principles as to materials, conformations, arrangements and relations of its parts. This, taken in connection with its controlling mechanism and its active operation, constitute it an engineering achievement which is the marvel of this fearfully and wonderfully constructed human organism. When this apparatus - worn, dishevelled, dete- riorated, disorganized-is presented for our remedial efforts, we must of necessity consider its engineering status and function; and our efforts if properly directed must be along the same lines and toward the same ends that nature has achieved in its construction and operation. There can be no doubt whatever, then, that engineering is another of the foundation principles on which we must base our efforts at oral restoration.

Not only must the body be nourished and strengthened for the practical purposes of life, but personal appearance is a matter of great importance in man's business and social relations and activities. In the matter of physical appearance the face is of chief concern; and located in the very center of the face is the dental apparatus. Probably no other organ or feature wields so great an influence toward making or marring facial harmony and expression. When the patient presents with nature's plans and purposes thwarted through deterioration, accident or loss it is the duty of the operator to establish harmonious conditions and relations as nearly as possible in accordance with nature's plans for the case in hand. All such matters having to do with cosmetic and esthetic values belong to the artistic side of our effort and their vital demands establish art as still another of the foundation principles on which we must base our efforts at oral restoration.

The putting into execution of these fundamental principles surgery, engineering and art is not a matter of theory alone and no amount of theoretical knowledge, unaided by technical skill, will suffice for its achievement. Inasmuch then as the operator must possess and bring into use his technical skill in every part of the undertaking - and inasmuch as the success or failure of his undertaking will depend in great measure upon the degree of excellence in the workmanship through which he carries out these practical details, and that this degree of excellence in the work- 
manship will frequently be the measure of the success of his undertaking, workmanship becomes of vital importance and is thus established as the fourth of the foundation principles on which we must base our efforts at oral restoration.

I am aware that in this recital of details I have brought to notice some matters so elemental as to make them seem scarcely worth the repetition; but I have been so because I believe one flagrant cause of failure in all lines of endeavor is that men do not think the problems that confront humanity back to their simple and elemental beginnings and out to their definite and inevitable conclusions. Instead of digging down to bed rock of fundamental reasoning for the foundation that will withstand the storms and stresses of the forces that continually strive against it, we buil! upon the sands of inaccurate observation and inadequate thinking. Is there any wonder that, when the rains fall and the winds blow, our superstructures fail and fall?

One of our great faults and failures is that we minimize the importance of the simple and elemental things; we feel somehow that we have outgrown them and that they are beneath our dignity when, as a matter of fact, they constitute the very vitals of our professional achievement.

We have established then, (1) surgery, (2) engineering, (3) art and (4) workmanship as the four foundation principles on which we must base our efforts at oral restoration; and this is what I have called the four-square foundation which must underlie our efforts. There have been other attempts to state fundamental principles but almost invariably the so-called principles have proven to be but details of one or another of the principles I have here laid down. For example, one essayist has specified physiological status of the field of operation as a necessary preliminary; but a moment's thought will show this to be but a detail of the surgical program. An- other insists on occlusion but occlusion is only one detail of the engineering procedure. So I believe it is with all matters pertaining to every side of oral restoration; analysis will show the four principles I have named-surgery, engineering, art and workmanship-to be complete and inclusive of all other details and so-called principles.

This brings us to our analysis of these vital principles in order that we may make a practical application of them to our undertakings. The limits of a single essay will not admit of carrying such an analysis to the minutest detail but I shall hope to proceed at least to practical lengths.

The first step in any surgical program comprises the cure or removal of pathological tissue and all products of degenerative processes, the correction of pathological conditions and relations, and the establishment of a physiological status in the field of operation. Applying this to the work of oral restoration we have a program which calls for the extraction of such teeth and roots as have become unfit for service or as constitute a menace to the systemic welfare, by reason of their own deterioration through disease or accident or because of the loss of contamination of their investing tissues; the treatment of all periodontic disturbances--pyorrhea, gingivitis, etc.; the sterilization of morbid periapical areas, the treating and filling of root-canals, the filling or inlaying of cavities, the correction by grinding or otherwise of traumatic occlusion and such corrections of malposition and abnormal relations as are practicable to the case in hand. With the field of operation freed from pathological conditions and a physiological status attained, as far as the circumstances of the individual case will admit, the further surgical effort may be considered under two heads: tissue conservation and prophylaxis. Such care as the case is presumed to have had to this point, has been merely preliminary to the actual work of constructing the restoration; and 
the tissues, both of the teeth and their surroundings, that remain are supposed now to be in a state of health. When we come to the work of preparing the abutment teeth for the reception of the bridgeanchoring attachments it is obvious that some tooth tissue must be destroyed; but the ends of good surgery require that the least possible amount, commensurate with obtaining a secure hold for the attachment, be removed and that all tissue vital to the needs of the pulp for protection from external influences shall be conserved. For example, the shell crown, which has become the standard bridge attachment for posterior teeth in the practice of so many operators, necessitates the destruction of much more tooth tissue for its proper construction than does the inlay type of attachment. Good surgery demands that that additional tissue shall be conserved, if the mechanical necessities of the case in hand will admit of it. That is what I mean when I speak of tissue conservation as one subdivision of our surgical effort. The final division of our surgical program is prophylaxis, by which I do not mean mouth sanitation, with which term it is so frequently confused, but I have reference to its true meaning, prevention, which is to say, the construction and placement of such restorations, and in such manner, as that the tissues both of the teeth and their investments and especially the pulps that remain after the work of preparation is complete, shall be protected, as far as the influence of the restoration extends, from irritation, contamination and deterioration.

The second of our principles is engineering. Everything that has to do with service and efficiency-that is building for service and the utilization of the restoration in the production of servicecomes under this head. Engineering may be divided, for the purpose of brief analysis into three parts. The first of these sub-divisions is the selection of the foundation. The one fixed and irrevocable thing in connection with bridge restora- tions is the strength available or attainable in the foundation. When we consider that in normal circumstances every tooth has its own foundation it is easy to understand that, in the case where some teeth are lost and their fellows are expected to support the structure made to take their places in service, however strongly anchored those remaining teeth may be, they constitute a foundation weakened to the extent of the number lost. In many cases it is further weakened by the loss of supporting structure about these remaining teeth. It is frequently possible to include additional teeth for anchorage purposes at one or both ends of the proposed restoration and by so doing to add greatly to the strength of the foundation, increase the usefulness and lengthen the life of the restoration. This is what is meant by selecting the foundation.

The second subdivision in the engineering program has reference to the handling of the foundation; that is to say, the preparation of each tooth or root, individually, in such manner as to conserve and utilize its greatest possible strength and so that the attachment constructed for it will exercise an unyielding grasp upon it. The type of attachment, whether internal or external, and the strain to be brought against the anchorage of the attachment in or on the tooth must previously be determined with reference to each tooth or root and each must be prepared in such form as that the attachment, once luted to position with cement, will not be dislodged by any stress normal to the case in hand.

The third subdivision in the engineering program pertains to occlusion; and here we have a matter directly related to the first subdivision-the selection of the foundation. Occlusal stress and foundation resistance are reciprocal forces and if we are going to produce both effciency through the occlusal performance and durability in our restorations these reciprocal forces must be balanced or coordinated. Wherever occlusal stress over- 
balances foundation resistance the ultimate result is the wearing down of that resistance, through overstimulation and trauma with the resultant tissue destruction and wreckage of the foundation, and consequently, of the restoration. Since this is inevitable, and since the avilable strength of the foundation $i ;$ the fixed point from which we must work, that available strength must be our guide in occlusal co-ordination. Normal occlusion is productive of normal service when supported by a normal foundation, as in the case where no teeth have been lost; but that same degrce of service or stress generated by such occlusal relations against a foundation weakened by loss of teeth, and frequently of supporting tissue as well, will, in many cases, be productive of strain, leading to trauma with its attendant train of evils. In such cases some way of altering the occlusal relations and of reducing occlusal stress must be found. Such reduction of occlusal stress will be at the expense, to be sure of part of the occlusal efficiency but this is a perfectly reasonable and justifiable state of affairs. It is unreasonable to expect, in any event, full efficiency from a weakened foundation. The suggestion is offered that there are several ways of reducing occlusal stress. Narrowing the occlusal surfaces below the normal; seeing to it that cusps are sharp and well defined; and in some cases leaving occlusal surfaces off entirely from one or more teeth, using facings only for the sake of the appearance. It cannot be too deeply impressed that the measure of strength and therefore of service is in the foundation; that we cannot enhance this beyond a certain maximum and that effort to produce for the patient more masticatory service or efficiency at the plane of occlusal contact than will balance the power of resistance inherent in any given foundation, will eventuate, sooner or later, in the destruction of that foundation. It is as inevitable as the working out of any other law in God's plan for the race. It is easy to see then of what vital concern engineering is in our scheme of things.

Coming to the third of our foundation principles, art, we find it simple enough of application if we comprehend its real meaning. Art has reference simply and solely to harmony, not to beauty as many might suppose, but to harmony. It has been said that the highest form of art is to conceal art. Our greatest service to our patrons from the esthetic point of view is to study the field of operation and its environment and to produce restorations in such keeping with them that their presence as substitutes for the natural organs will not be detected. That this is quite impossible of complete realization in many cases should not in any case deter us from keeping the goal before us as our ideal and reaching as far in that direction in every case as the circumstances of the individual case will admit. When we speak of harmony we mean harmony in character, conformation, size and color of the teeth; relations of the teeth; surface markings, especially those representing wear, erosion, etc., in cases where natural organs remain to be used as guides in these matters. Where there are no such guides the shape and contour of the face, length and fullness of lips, size of arches, age, complexion, habits, etc., of the patient all must be considered and influence our selection. We mean harmony also-as far as it is possible to attain it, between the materials used in the superstructions and their environments. Much more might be written, but these are the keynotes as it were-remembering that naturalness of appearance, and not beauty, is the desideratum except where the restoration is to be set amid beautiful surroundings. Even amid beautiful surroundings beauty does not constitute art simply because it is beauty, but because of its harmony with its environment.

The fourth and last of our foundation principles is workmanship. Surgery, engineering and art are all departments where theory without practice is merely 
word without deed. Knowledge and understanding are necessary preliminaries, but they must find expression through the technical details of mechanical execution before they become realities; and this mechanical execution is the part that the workman plays in our program. This gives workmanship a place of tremendous importance. No chain is stronger than its weakest link. By the same token a combination of the greatest theoretical understanding and poor execution will not make good bridge-work, which is only as good as the execution after all. Good workmanship then, in all the departments of our undertakings is vital to the success of any restoration. Since this is true, it stands as a corollary that the simpler the methods employed and the fewer and simpler the details of construction, the better any workman can execute them and the greater the number of workmen who can execute them well. This constitutes a direct challenge to those types, systems and methods that necessitate the use of many parts, many and complicated details of construction and much paraphernalia. Most of these things are but commercial parasites on the body professional and I believe that ultimately we shall cleanse ourselves of their loathsomeness. Whatever makes for simplicity makes for greater accuracy and consequently for better workmanship at the hands of any operator; and for a greater proportion of operators capable of good workmanship.

Thus we have established our standard of perfection for bringing into being the productions that our responsibility as members of the healing art demands of us.

We know that the degree of excellence with which the details of all these foundation principles are put into execution is the measure of success of the finished product. And we know that the simpler these details are kept the greater the assurance of excellence in the workman- ship. This seems to me to be the acme of simplicity as a set of rules or a standard of perfection to guide us in all our efforts. With these specifications before us it seems a fairly simple matter to look into the oral cavity, to analyze the conditions and relations found there, to co-ordinate our findings, to study the possibilities of the individual case and determine upon a plan of procedure. Through such an understanding as we should have from this elemental study of conditions, relations, desiderata and possibilities many of the perplexities and difficulties with which we have unwittingly surrounded ourselves should become matters of the past and oral restoration a pleasure rather than a burden.

It will be observed that I have not included in this standard of perfection any details of technic for any part of these operations. Principles are based upon matters of vital concern; they are unchangeable and should be inviolable. But technic is an expression of individuality, preference, opportunity and every man should be free to give substance and vitality to principles - to reach the goal of service to his patient, through whatever avenues of technic are most convenient to him or best suited to his purposes.

But if our efforts are to reach the plane and deserve the name of service our technic must be based on principles, or if you will, a standard of perfection. When we arrive at this stage-when we take ourselves more seriously as an integral part of the healing art, we will learn to care for the pathological processes that come within our responsibilities in the genuine spirit of service, the disorganized mechanism as a scientific achievement and the degenerated esthetic entity on the exalted plane of art for art's sake. Our material rewards will then be the reaction from unselfish performance rather than the paramount issue of purely business transactions. Only then will the servant be worthy of his hire! 